\title{
Are you into lexicophilia?
}

It is our aim to be adventurous in the topics we select as the cover themes of English Today, and we welcome readers' suggestions as to the kind of things we should be dealing with both in these and in ET's other pages. The content of many of our ten issues to date has been decisively influenced by individuals writing in to the editor. Along with our bulging post-bag - 10 pages in this issue (counting Angles of Vision, Kaleidoscope, Lexicon and News) - these suggestions indicate a growing reader involvement in the creation of each issue. This is the direction in which we hoped the review would move when we were planning it in 1984.

Some of our cover themes are global issues (in every sense of that word): worldwide literacy, comprehensive views of the teaching of English, international campaigns for Plain English, the question of the effect of English on endangered languages, and so forth. In only one issue to date have we looked - in that instance historically - at specific products: the usage books so prolifically displayed for the curious, and the insecure (ET7, July 86).

There, however, apart from comments on the style and content of various past and present bibles of usage, we made no specific recommendations, drew up no 'league tables', and did not point in any direction that we or our contributors felt might be the right direction for books on English usage to take.

In this issue, the approach to a particular kind of traditional English-language product has been different and we hope it will be seminal. It has also not been easy to organize, as models for the comparative assessment of dictionaries are few and far between. In addition, although it would have been good to incorporate a broad users' survey into our review of dictionaries, this proved to be beyond the resources of $E T$, with the result that we have confined comment to three individuals (Professor Richard Bailey, Dr Reinhard Hartmann and the editor) who in their daily lives for many years have been exercised over the nature and uses of wordbooks. As far as we know, nothing like this has been attempted before, but even so it is only a beginning, and serves to point up the lack of facilities and vehicles for the assessment of tools of such central significance in our culture. By and large, apart from one-off reviews of single dictionaries and a quick flip through a few leading contenders on the shelves of booksellers, there are no facilities and vehicles which allow the interested user to decide which dictionaries do what most effectively.

When we first mooted the idea of a review of dictionaries an internationally known and greatly respected lexicographer immediately assumed that we would devote the whole of one issue of $E T$ to the job. That could not be; if for no other reason than that many of our readers may not be 'into' lexicophilia. As was pointed out, however, it meant that we could hardly do justice to the immense richness of the market.

That is true, and the editorial decision was to cover only one genre: the larger 'desk' or 'family' dictionary, caught between the great unabridged works and the handier concise and pocket volumes. From the contenders in this area the reviewers agreed on eight: four published in the United Kingdom, three in the United States, and one in Canada. It is, we hope, a reasonably tactful start, and readers' responses will show those directions in which you would like the project to develop (if indeed such a development interests you).

Apart from weighty word tomes, ET10 varies the mixture as before. Jargon comes in this time as officialese (Roger Elliott, pp. 19-21). Geography and history include the Norse heritage, especially in the variant called Norn in the Northern Isles of Scotland (Joyce Killick, pp. 24-25). Technological change is Fraida Dubin's concern (with telephone talk, pp. 28-30), and purism takes on a new - or a forgotten? - dimension in Jean-Marc Gachelin's piece on William Barnes and 19th-century vernacular enthusiams. We also have a response to Stephen Wade's article on Anglo-Irish literature (ET8); it is by Eoghan Mac Cormaic and was written in $\mathrm{H}$ Block $I$, in Northern Ireland (pp. 32-33). Taking account of all the omalies and hopefullies, dying apostrophes and high-flying artificial languages, the Golkarizing of remote islands and the Trance'n'dental aspects of bioprospecting, it is difficult to decide which is stronger in the English language - its themes or its variations.

Tom McArthur

The editorial policy of English Today is to provide a focus or forum for all sorts of news and opinion from around the world. The points of view of individual writers are as a consequence their. own, and do not reflect the opinion of the editorial board. In addition, wherever feasible, ET leaves unchanged the orthography (normally British or American) and the usage of individua contributors, although the editorial style of the magazine itself is that of Cambridge University Press.

\section{A Call for Papers}

In $E T$ 's files we have cuttings/clippings from a wide range of British and North American newspapers, and a scattering of material from many other sources. If readers would care to add to our files by sending in occasional (titled and dated) material from their local newspapers, etc., or even the odd complete sample of a specially interesting periodical, this would be a great help in widening the range of usage which we can quote in From Our Files.

Letters to the editor should be addressed to a branch of Cambridge University Press (for forwarding), or directly to:

\section{Dr Tom McArthur}

Editor, English Today

22-23 Ventress Farm Court

Cherry Hinton Road

CAMBRIDGE CB1 4HD

England 